dents had trouble in not being able to see both the pins in the line in which they had been placed. This was avoided in later classe. by directing them to place one pin in position, and while looking through the prism adjust the other, until both pins could be seen in line.

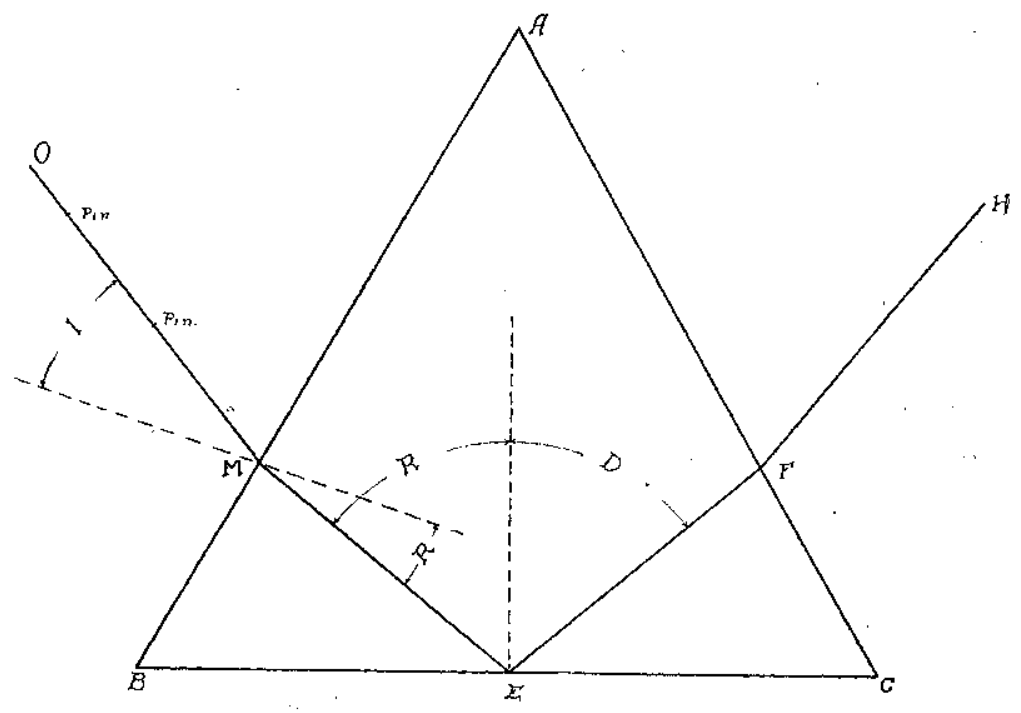

\title{
AIR PRESSURE-HOW IT WAS DISCOVERED-STORY OF THE BAROMETEK.
}

By Merton C. Leonard, Dickinson High School, Jersey City, N. J.

\section{INTRODUCTION.}

There is something cultural and satisfying in learning how the great scientists of the past "thought it out," and what experiments they devised to prove or disprove old theories. It is stimulating to learn of their boldness in challenging the verdict of the age, and of their sublime faith that truth would ultimately triumph over error, prejudice and superstition.

Teachers who become stimulated to admire whole-souled devotion to truth for the sake of truth unconscionsly become better companions for their pupils.

When a science teacher finds his work becoming monotonous or stale, let him but familiarize himself with the historical background of the science he teaches. This will give him a new 
resource upon which he may draw, and thus wonderfully enrich all his teaching. In oral instruction, the story, well told, alwavs finds a welcome. It adds one hundred per cent to the interist and value of the Torricellian experiment to tell the story, somewhat as given below, while the experiment itself is being mad: before the class.

This story, adapted (with extensive modifications and additions) from the account in Cook's Religion and Chemistry (now out of print) is offered here partly from the conviction that many teachers will find it of practical value in the classroom, an 1 partly to preserve in print what is probably the best account of the work of Torricelli and Pascal on the subject of air pres. sure to be found in the English language.

The following accounts of air pump experiments were taken with some changes, from Cajori's History of Physics-a boo: that all teachers of science may often refer to with profit.

Weight, Pressure and Expansibility of the Ali.

That air has weight may be proved by weighing a flask when full of air and again after exhausting the air. Galileo proved the same point, by weighing "a glass balloon flled with air under ordinary pressure and then with air under high pressure."

Atmospheric pressure is illustrated by the action of the common lift pump, by the great force required to separate the Magdeburg hemispheres, by the hissing sound which you hear as you begin to open a can of preserves, by the water remaining in the inverted tumbler that is capped by a piece of moist cardboard, and other experiences even more familiar to us.

About the middle of the seventeenth century, when the truth of atmospheric pressure was just dawning upon the human mind, Guericke - the inventor of the air pump-made for the first time many interesting experiments based on air pressure. From a tight wine cask filled with water, he attempted to remove the water without allowing air to get into the cask. By using the force of three strong men, he succeeded in drawing out most of the water, whereupon "a noise was heard as if the residual water within were boiling violently, and this continued until air lad replaced the water which had been pumped out."

"The leaky wooden cask was then replaced by a copper globe. and water was drawn out as before. At first the piston moved easily, but later the strength of two men could hardly move it, when suddenly with a loud clap, and to the terror of all, the sphere collapsed." 
But perhaps Guericke's most famous experiment was the one with the large Magdeburg hemispheres performed at Regensburs in 1654 before the members of the Reichstag and Emperor Ferdinand III. The hemispheres had a diameter of nearly fifteen inches and, according to the calculations of the experimenter, a force of 2,686 pounds was needed to overcome the atmospheric pressure which held the hemispheres together. They were pulled apart by the combined strength of sixteen horses, four pairs being attached to each hemisphere. Undoubtedly, fewer horses would have sufficed. It is probable that the larger number wa: used more for dramatic effect than from necessity."

Another experiment, illustrating the power of air pressure sometimes called "suction," is described as follows: A cylinder of a large pump had a rope attached to its piston which led over a pulley, and was divided into branches on which twenty or thirty men could pull. As soon as the cylinder was connected with an exhausted receiver, the piston was suddenly pushed down by the atmospheric pressure, and the men at the ropes were suddenly pulled forward.

With air pumps of various types which Gucricke invented, he was able to produce a vacutm with ease, and thus he could make many experiments to find out how things behave in an empty space. In this way it was learned that a clock cannot be heard when it strikes in a vacuum; that nothing wil burn there; that a mouse shows signs of distress and lives but a few moments: "that a bird opens its bill wide, struggles for air, and dies; that fishes perish; that grapes can be preserved six months in r'acuo.",3

The Barometer-How It Was Discoverem That It Is Atmos. pheric Pressure That Stiports the Water in a Lift Pump and the Mercury in a Barometer.

The effects of air pressure are so numerous and so conspicuous that even the ancient Greeks sought a theory to explain such things as the action of a siphon, and of a pump; the fact that water is supported when a full inverted bottle is placed in a basits of water; or when a full tube, open below and closed above, is similarly placed; and the running out of the water, in this in stance, when the top is opened. These ancient philosophers noticed also that space was always filled with some material suth-

1Adapted from Cajori's History of Physics.

2 Physics, by Mann \& Twiss. Cut, opposite page 125.

'Cajor's History of Physics, pages 68, 70 . 
stance, and that the moment a solid body was removed, air or water always rushed in to fill the empty space. Hence they concluded that it was a universal law of nature that space could not exist unoccupied by matter. This simple theory they expressed in the phrase-Nature abhors a racuum. Making use of this theory, they explained the rise of water in a lift pump by declaring that, as from the nature of things a vacuum could not exist, the water necessarily filled the space deserted by the piston.

This interesting theory, though imperfect and 'wrong because it introduced the idea of an emotion, horror, to account for physical facts, yet served the purpose of natural philosophy for about two thousand years, and dotibtless it would have served longer had it not been discovered that under certain conditions nature does not abhor a vacuum.

Near the middle of the seventeenth" century, some engineers were employed by the Duke of Tuscany to sink a well in the neighborhood of Florence to an unusual depth. They finished their task, but on adjusting the pump they found to their surprise that it would not work. In spite of their efforts, the water would rise only about thirty-three feet, and by no ingenuity or skill could they raise it an inch higher. Here then, in the cylinder of the pump, between the top of the water column and the piston, was a vacuum which nature refused to push the water into although plenty of water was right at hand. Thenceforth science had a new fact to deal with; and the old theory could no longer stand. The baffled engineers, more disgusted with nature than nature was with the vacuum in their pump, applied to Galileo, then an old man, living in his villa, on the brow of a hill near by. He could not aid them, but he is said to have replied, half in jest, and half in earnest, that nature did not abhor a vacuum above ten meters. Had this incident occurred earlier in his career, it is likely that Galileo would have arrived at the new truth that was just about to dawn on the scientific world, but now the vigor of his manhood was spent; he had done his work and was peacefully resting from his life's labor, and calmly awaiting the close.

But the key which the incident had furnished was not lost. It passed into able hands, and it was the fortune of Torricelli; Galileo's best pupil, to unlock the secret. This young Italian philosopher, whose clear intellect had been trained in the mechanical philosophy of his great master, saw at once that a column 
of water thirty-three feet high, and no higher, could not be sus. tained in a cylindrical tube by a mere phrase or emotion. This effect, he reasoned, must be the result of some mechanical force equivalent to the weight of the mass of water sustained. It was not difficult to prove the correctness of this reasoning, for it was evident that if a column of water was sustained at the height of thirty-three feet in the suction pipe of a pump by a constant force, the same force would sustain a column of a heavier liquid only to a proportionally less height. If he shotuld use a liquid twice as heavy as water, the column would be only one-half as high as the water column; if three times as heavy, then only onethird as high, etc. So Torricelli tried mercury-a liquid thirteen and one-half times as heavy as water-and the result was as he had anticipated. The force-whatever it was-which raised the column of water thirty-three feet could raise a column of mercury only to the height of about thirty inches, which is 13.5 times less than thirty-three feet. Torricelli did not, however, make this experiment with a pump, but with an apparatus of his own devising, much simpler and equally effective.

He took a long glass tube, open at one end, filled it with mercury and, having closed the opening with his thumb, inverted the tube, and plunged the open end into a basin of mercury; on removing his thumb, the mercury, instead of remaining in the tube, and thus satisfying nature's abhorrence of a vacuum, fell, as he expected, and after a few oscillations, came to rest at a height of about thirty inches above the level of the mercury in the basin. The correctness of his induction having been thus verified; Torricelli at once concluded that it must be the pressure of the air which sustained both the water in the pump and the mercury in the tube. This experiment was made in Florence in 1643, and when the news of it spread among the scientific men of Europe. it exciled a great sensation, but, as might naturally have been expected, the old horror-of-a-vacuum theory was not easily displaced, and Torricelli did not live to see his ofinion generally received. It was left to the celebrated Blaise Pascal-ma distinguished physicist of France-to convince the world that Torricelli was right, and this he did by one of those master strokes of genius which at once silence controversy.

"If," said Pascal, "it be really the weight of the atmosphere under which we live that supports the column of mercury in Torricelli's tube, then, at a higher altitude, the column ought to be shorter, for, by transporting the tube upwards, we leave above 
it less air that can exert pressure upon it. Accordingly, he car ried the tube to the top of a church steeple in Paris, and observed that the mercury fell slightly, but not being satisfied with this indecisive result, he wrote to his brother-in-law, M. Perrier, who lived near the high mountain of Puy de Dome in Auvergne, asking- him to make the experiment there where the result would bc more decisive. "You see," he writes, "that if it happens that the height of the mercury at the top of the hill be less than at the bottom (which I have many reasons to believe, though all those who have thought about it are of a different opinion), it wilt follow that the weight and pressure of the air are the sole cause of this suspension, and not the horror of a vacuum; since it is very certain that there is more air to weigh on it at the bottom than at the top; while we cannot say that nature abhors a vacuun at the foot of a mountain more than on its summit." M. Perrier, Pascal's correspondent, made the observation as requested, and found a difference of three inches of mercury, "which," he says", "ravished us with admiration and astonishment."

In passing, we should note that this new truth was arrived at not by discussion, but by experiment. Guericke, the scientist who made so many experiments with air pumps. especially realized the futility of talking, and the value of $d o i n g$. for, he said, "Oratory, elegance of words, or skill in disputation avails nothing in the field of natural science." In àn age when it was regarded as a desecration to dissent from the teachings of Aristotle, only men of exceptional talent, originality and moral courage dared to go directly to nature for answers to the great philosoplical questions of the day. Hence we are indebted to these great men not less for their fearlessness than for the usefulness of the truths they discovered, and the help they gave as pioneers in bringing into fashion the experimental method of studying riatural science. 